\title{
ASSESSMENT OF SOCIAL RETURN ON INVESTMENT FROM THE UTILISATION OF OIL PALM'S RESIDUES
}

\section{WISAKHA PHOOCHINDA*}

\begin{abstract}
This study aimed to investigate utilisation of residues from oil palm in local communities and to assess the social return on investment (SROI) from this utilisation. Data collection was undertaken in Thailand through interviews with policy-makers, practitioners, professionals from oil palm cooperatives, the Oil Palm Research and Development Centre, the Department of Agriculture, the Office of Agricultural Economics, and the Federation of Thai Industries. Questionnaires were given to oil palm growers in eight provinces, totalling 80 samples. Interviews were conducted with five palm oil mills. The SROI for various methods of the utilisation was calculated. The results showed that many options for utilisation included tillage, chopping up and letting residues be digested, using empty fruit bunches for mulching, producing biomass energy, mushroom cultivation, and for use as animal feed and compost. As for the SROI of utilisation of oil palm residues, it was found to be between 0.35 and 2.86. The majority of the utilisation options yielded an SROI lower than 1. The utilisation of oil palm residues to produce animal feed yielded the highest SROI of 2.89 , whereas the use of oil palm residues to produce hard fibreboard resulted in the lowest SROI at 0.35.
\end{abstract}

Keywords: SROI, oil palm, residues.

Date received: 30 April 2018; Sent for revision: 22 May 2018; Accepted: 8 October 2019.

\section{INTRODUCTION}

The Ministry of Agriculture and Cooperatives of Thailand has formulated measures to support the use of alternative energy through the Alternative Energy Development Plan: AEDP2015, focusing on the optimisation of the production of energy from raw materials that are based on domestic alternative energy, the development of the potential to produce alternative energy with appropriate technology, and the development of alternative energy for the common benefit of communities in the social and environmental dimensions (Department of

Graduate School of Environmental Development Administration, National Institute of Development Administration, 118 Moo3, Serithai Road, Klong-Chan, Bangkapi, 10240 Bangkok, Thailand.

E-mail: wisakha.p@nida.ac.th
Alternative Energy Development and Efficiency, 2015). Oil palm is one of the major means of obtaining energy and is one of the economic crops currently promoted for cultivation as it can be used to produce biodiesel. Oil palm is also processed into various products, such as cooking oil, soap, detergent, cosmetics, etc. It is also used as a raw material in the food industry for the production of ice cream, margarine, sweetened condensed milk and others. Due to the high demand of oil palm at national and global levels, the Ministry of Agriculture and Cooperative has developed a strategy to expand the area of oil palm cultivation to 1.16 million hectares by 2026. Farmers, therefore, increasingly turned to oil palm cultivation.

In 2015, the area of oil palm cultivation in Thailand totalled 751520 ha, up from 121600 ha in 2014 (Office of Agricultural Economics, 2015). Oil palm has, thus, become an important crop for the 
country's development and oil palm production have increased to support global and national demand. Accordingly, the residues from oil palm cultivation and palm oil mill have increased annually. Moreover, oil palm producers have encouraged the study of the most effective use of oil palm residues from both oil palm plantations and palm oil mills. Many agencies have carried out research using different types of oil palm residues to produce value-added products such as old oil palms, fronds, empty palm bunches, fibre from oil palm, waste from decanter, oil palm kernel meal, palm kernel shells, and wastewater from palm oil mill processes. Appropriate guidelines have been formulated to make use of these agricultural and industrial residues in order to minimise the waste being released into the environment and to gain economic returns.

Thailand has formulated a policy to promote the cultivation of oil palm as an important economic crop. Its Plan to Develop Oil Palm and Palm Oil Industries(2013-2017), promoted oil palm cultivation in appropriate areas according to the announcement of the Ministry of Agriculture and Cooperatives in 2013. Further, Thailand has promoted oil palm cultivation in new areas, accounting for 32000 ha a year, totalling $160000 \mathrm{ha}$; and the replanting of old oil palm, accounting for 16000 ha a year, totalling 80000 ha. The rehabilitation of old oil palm plantation has led to an increase in their production efficiency to achieve the yields of 0.19$0.22 \mathrm{t} \mathrm{yr}^{-1}$ per the extraction oil rate of $18.5 \%$ (Office of Agricultural Economics, 2014) with quality based on international standards.

Each cultivation and utilisation process of oil palm utilisation in various industries generates large amounts of residues. Phoochinda (2015a) has synthesised knowledge on oil palm and its utilisation in the Handbook of Integration to Strengthen the Oil Palm Industry in ASEAN Economic Community $(A E C)$. The results revealed that most research focused in the mid-stream processes of oil palm industry, meaning the operations of the industrial system prioritised the increase of yields, reduction of production costs, and the use of residues such as wastewater, sludge, oil palm fibre, and other byproducts due to the large amount produced every year. There was little information directly related to oil palm growers, such as the use of empty fruit bunches and fronds from oil palm to create economic value, increase income, and reduce environmental impacts.

Researches conducted in Malaysia and Indonesia have revealed the use of residues from the oil palm industry, such as the use of trunks or fronds for mulching, processing for roof-covered materials, furniture, and the promotion of the use of empty fruit bunches via oil extraction as fertilisers. Thailand does not have such concrete support in the form of research that explores the benefits and returns of the use of residues from oil palm in various dimensions. In the past, researches tended to focus on specific fields of study, such as economic returns from each process, the environmental impact from each process, and the investors' return on their operations. However, research on the integration using palm residues should cover threes development dimensions, namely, the economic, social, and environmental dimensions. This is to encourage growers to make comprehensive use of oil palm and enhance the potential as well as future sustainability of domestic oil palm development.

Development must include the entire systemfrom producers to consumers. With increased demand for the use of palm oil, growers in the upstream oil palm industry must increase their production accordingly, resulting in increased agricultural residues from oil palm plantations. At the same time, oil palm growers in Thailand face long-term oil palm cultivation problems, including higher production costs, price fluctuations in line with global markets, uncertainty in government policy at certain points of time, smallholders that face the serious problem of high production costs in comparison to industrial entrepreneurs, and high risks in operations. Some studies revealed that currently growers and supporting agencies of growers have employed the oil palm farming residue to strengthen the growers in terms of household applications and operations in community groups. These include straw mushroom cultivation from empty fruit bunches, the production of compost from the residue of fronds and empty fruit bunches, and the production of animal feed for ruminants. For example, there has been the promotion of comprehensive oil palm production of communal enterprises in Ban Khuan Sian, Moo 5, Khao Khen Subdistrict, Plai Phraya District, Krabi Province; and straw mushroom cultivation from empty fruit bunches to generate additional income for community members operated in Nakhon Sri Thammarat, Chumphon, Surat Thani, Lopburi, and other provinces similarly. Moreover, the Department of Livestock Development has recommended that growers use oil palm fronds as animal feed for ruminants, such as cows and goats, to reserve them as animal feed during natural disasters, thanks to the numerous nutrients of oil palm fronds.

Oil palm residues can be used for many purposes. If growers can secure oil palm residues by cultivating oil palm appropriately, their communities can utilise the residue along with concomitant environmental protection and cost efficiency. This will lead to sustainable occupations and reduce the risk of income uncertainty or insufficient compensation, as well as the risk of failure in operations that might require assistance from the government or related agencies. The importance of the opening up of free 
trade under the context of the AEC will hasten the creation of knowledge in Thailand to strengthen the country's growers and the economy in the future.

The objectives of this article are to study on the comprehensive use of residue from oil palm planting in order to examine the comprehensive use of oil palm residue as alternatives in local communities and to assess SROI from the utilisation of oil palm residue. Such a study would contribute to the efficient management of oil palm residues appropriate for the communities and in line with the objectives of Thailand's national development, thus, leading to sustainable development.

\section{LITERATURE REVIEW}

Many researchers have investigated the utilisation of oil palm residues (Phoochinda, 2015a); however, few researchers have investigated the benefits of oil palm residues. In this study, the benefits of the utilisation of oil palm residues are quantified and so if there are various alternatives for the use of oil palm residue, the benefits can be compared in terms of the SROI, the key issue of this study. There have been many studies concerning guidelines for managing oil palm, its by-products, and their residues. As mentioned by Papong et al. (2014), palm oil is used as energy and food, and most wastewater from oil palm production is used as biogas. This is in accordance with the notion of Malakul et al. (2011), who studied the production of biofuel from agricultural products and found that, regarding energy assessment, the production of biodiesel from palm oil had a net energy value and net energy ratio of 21.6 and $2.5 \mathrm{MJ}^{\text {litre }}{ }^{-1}$ of biodiesel respectively, demonstrating good energy efficiency. The findings of Malakul et al. (2011) on environmental assessment of biofuel revealed that most environmental impacts came from the production process due to the high use of fossil-based energy in its production.

In addition, Phoochinda (2015b) conducted a study on the guidelines to promote the oil palm agricultural sector to reduce greenhouse gases (GHG) based on Thailand's standards. The results showed that the guidelines involved creating a mechanism of cooperation to reduce the emission of GHG and to reduce the oil palm production costs by supporting the establishment of an 'oil palm plantation model' as a knowledge centre for growers, supporting soil and leaf analysis for correct use of chemical fertilisers in oil palm, and encouraging the combined use of organic and chemical fertilisers to increase the richness of the areas used for oil palm cultivation. Moreover, the emission of GHG derived from oil palm cultivation should be reduced by encouraging growers to participate in the standard certification of oil palm cultivation, such as oil palm cultivation standards, for example, through Good Agricultural Practices (GAP), with incentives such as higher prices, regulations to preserve communal forests to prevent encroachment on forests or preserved forests, and the promotion of standard certification of GHG emissions among oil palm growers. Moreover, the guideline included researching and developing technology to reduce GHG emissions from the growing of oil palm by promoting the development of oil palm with high yield output, reducing the use of chemical fertilisers, promoting the development of fertilisers or nutrients from oil palm residues such as developing fertilisers from oil palm fronds or empty fruit bunches, and promoting the use of technology to plan oil palm cultivation, such as the use of Geographic Information System (GIS) to select suitable areas.

A study by Phoochinda (2015a) also mentioned integration for strengthening the oil palm industry in the context of Thailand and AEC. The researcher stated that, regarding the agencies responsible for policy formulation, research should be conducted to develop the quality of output and to increase production efficiency to a competitive level in order to create sustainability for the oil palm industry in the future, both as food and energy crops, and guidelines should be put in place to reduce the environmental impacts from the oil palm industry regarding the entire system. As for the growers and their groups, they have faced problems concerning the loss of profits, lack of knowledge and understanding of the production of oil palm in terms of the whole system on a commercial scale, and also regarding oil palm seeds, fluctuations of oil palm prices, and the competition of growers for high quality output.

Therefore, academic knowledge and appropriate technology should be provided for the management of the production of oil palm. Techniques for selecting seeds and appropriate areas for cultivation are very crucial. These ensure economic returns and the grouping of growers in order to strengthen their knowledge and negotiation strength in oil palm markets. In terms of oil palm producing and extracting plants and by-product industries, they have faced problems of unsuitable locations, purchase points, and the environmental impacts from the oil palm industry. Therefore, a guideline should be formulated in order to set up a purchase point of fresh fruit from growers and the establishment of by-product industry from oil palm; and a model for the sustainable operation of the oil palm industry should be developed. The recommended guideline to create knowledge would lead to the robust integration of the oil palm industry in terms of the entire system.

Choong and Makay (2014) recommended a guideline to create sustainability for the oil palm industry in Malaysia by using the principle of 
carbon footprint to assess the entire life cycle of acquisition and production of products. This reflects an awareness of the problems regarding environment resulting from oil palm growers, oil palm processing industry, and consumers. The important information for the consideration consists of: 1) direct information on the impact of GHG emissions from oil palm industry, such as land use, energy consumption, and waste management; 2) information as summarised by palm oil mills and refining factories for consideration, such as information on energy consumption, waste management within factories, and the impact from production within factories; and 3) related industrial sectors such as the food industry with oil palm as a component.

Aeumchan (2009) conducted a comparative study on the use of energy, economic returns, and environmental impacts in the production process of biodiesel on commercial and communal scales in Thailand. The study found that the biodiesel producing plants for commercial used crude palm oil as the raw material to produce quality biodiesel both at appropriate quantities and qualities as stipulated by various standards.

In conclusion, the literature review on the concepts, theories, and related research indicated the methods of oil palm farming management; guidelines on the use of residue from oil palm and palm oil mills; concept of community economy; SROI; and assessment of the environmental impacts through the life cycle analysis of the oil palm

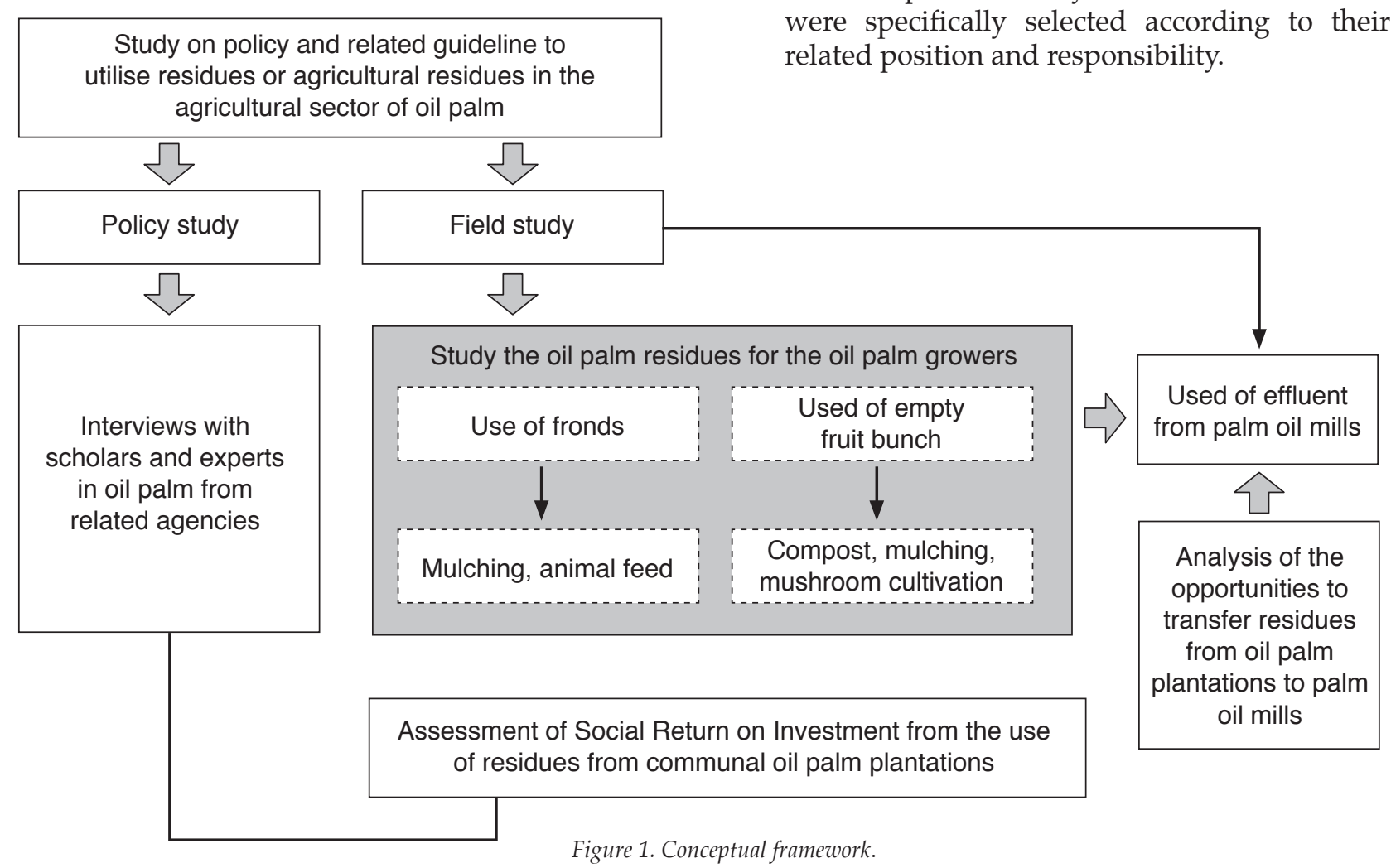

industry, policy, plans, researches and measures related to the oil palm industry. Previous researches examined technology on the use of residue from oil palm and products, efficient use of oil palm, waste from oil palm, and by-products for energy and food.

\section{METHODOLOGY}

The conceptual framework on the study of assessment of SROI from the utilisation of oil palm residue is illustrated in Figure 1.

1. Review concepts, theories, researches, policy and measures on the use of residue from oil palm related to the oil palm industry, within and outside Thailand, especially countries that are leaders in the oil palm industry, such as Indonesia and Malaysia, as well as study Thailand's oil palm strategies and the concept of SROI.

2. Study in-depth information from scholars and experts in agencies related to oil palm production both at community and national levels, such as cooperatives of oil palm growers, research and development centres of oil palm, the Department of Agriculture, the Ministry of Agriculture and Cooperatives, the Federation of Thai Industries (Palm Oil Industry Club), the Agricultural Research Development Agency (public organisation), and other agencies in Thailand through interviews to acquire information on policy, measures, and implementation guidelines on the use of residue from oil palm. All key informants mentioned were specifically selected according to their related position and responsibility. 
3. Select sample groups of oil palm growers from eight provinces, each province with 10 sample groups already using oil palm residue, in order to create a guideline for the utilisation and operation of oil palm residues, divided into three regions (the central plains, consisting of Pathum Thani and Saraburi; the east, consisting of Chonburi and Rayong; and the south, consisting of Chumphon, Surat Thani, Songkhla, and Trang) and to assess SROI according to operations based on useful principles, such as the use of fronds, empty fruit bunches, and other uses. The eight provinces were selected as they are at the top rank of Thailand's oil palm growers as well as representatives of each region of Thailand.

4. Field interviews with five palm oil mills to examine the linkage of the use of oil palm among growers, sale and purchase points, and palm oil mills.

5. All information gathered will form a guideline on the use of oil palm residue suitable for potential growers through analysis and synthesis to form an operational framework appropriate to an oil palm planting management system, through case studies, the comprehensive use of residue from oil palm in communities, and the calculation of SROI. In order to calculate SROI, the discounted value of benefits was divided by the total investment (fix and operation costs) (Social Value UK, 2019).

SROI ratio $=$ Present value $/$ value of inputs

For example, in order to use sludge from raw palm oil, the total investment includes land, labour and/or capital investment, and equipment, while there are three benefits in term of economic, social, and environmental from the utilisation of the sludge, such as selling compost, having an income from being a study centre, and selling carbon credits from utilisation of compost.

As the equation of SROI is simple, growers can collect and calculate the total cost/investment and the value of benefits obtained from the utilisation of oil palm residues. In addition, the SROI is better than the return on investment (ROI) as it includes the three benefits mentioned above, while the ROI involves only economic benefit. Regarding the comparison of each method for oil palm utilisation, the SROI can be applied as it has no unit and can be calculated based on the benefits and costs resulting from each method of utilisation.

\section{RESULTS AND DISCUSSIONS}

\section{Comprehensive Use of Oil Palm Residue in the Community}

This study included a literature review, interviews with scholars and agencies related to oil palm production and palm oil mills. Field surveys of oil palm farms and interviews with oil palm growers were conducted in order to learn about the use of the oil palm residues such as old oil palm, palm fronds, empty fruit bunches, palm kernel meal, waste palm fibre, palm kernel shells, sludge from palm oil mills, and effluent from wastewater treatment ponds of palm oil mills. The residue can be used in various applications, such as the cultivation of straw mushrooms using empty fruit bunches, oil palm fronds for animal feed, empty fruit bunches for mulching, the production of compost from palm oil mills residue, the accumulation of oil palm fronds to be used as fertiliser and to preserve moisture in the soil, the production of compost from empty fruit bunches, the production of hard fibreboard from old oil palm, biomass fuel from palm kernel shells, and the production of biogas energy from effluent in wastewater treatment ponds, as summarised in Table 1.

In Table 1, the oil palm residues can be variously utilised and depends on the growers, the support from related agencies, and the access to raw materials and resources in the growing areas. If all residue can be utilised, it will reach zero waste, which is the best means to utilise oil palm. However, if the residue is not utilised, growers will dispose it as garbage and, thus, there will be disposal and treatment costs. In addition, the unused palm residue can bring to GHG, leading to global warming.

TABLE 1. UTILISATION OF OIL PALM RESIDUE

\begin{tabular}{ll}
\hline Residue & Utilisation \\
\hline $\begin{array}{l}\text { Old oil palm } \\
\text { Palm fronds }\end{array}$ & $\begin{array}{l}\text { Hard fibre board } \\
\text { Animal feed, accumulated on the ground to add nutrients } \\
\text { and to preserve moisture to the soil }\end{array}$ \\
$\begin{array}{l}\text { Empty fruit bunches } \\
\text { Palm kernel meal }\end{array}$ & Cultivation of straw mushrooms, compost, mulching \\
Waste palm fibre & Animal feed, compost \\
Palm kernel shells & Hard fibreboard \\
Sludge from palm oil mills & Biomass fuel \\
Effluent from wastewater treatment ponds & Compost \\
\hline
\end{tabular}




\section{Assessment of the Economic, Social and Environmental Returns on Investment from the Utilisation of Oil Palm Residue}

The SROI in the present study was calculated based on the three benefits from the utilisation of oil palm residue, including economic, social, and environmental. Hence, it can be used as an indicator of sustainable business as the SROI concerns three aspects as mentioned. The SROI from the use of oil palm residue such as the cultivation of straw mushrooms from empty fruit bunches, the use of oil palm fronds as animal feed, the use of empty fruit bunches to cover the soil, the production of compost from the residue from palm oil mill, the accumulation of oil palm fronds to be used as fertiliser and to preserve moisture in the soil, the production of compost from empty fruit bunches and the production of hard fibreboard from oil palm had an SROI of 2.34, 5.47, 0.84, 0.70, 1.44, 0.80 and 0.35 , respectively. The use of oil palm residue using oil palm fronds as animal feed obtained the highest SROI as oil palm fronds are trimmed many times in a year to produce animal feed. However, the investment in purchasing a branch shredding machine takes place only once. As summarised in Table 2, the SROI from the use of oil palm residue achieved small value because some utilisation guidelines required high costs.

According to the results of the study, oil palm residue can be used in the following ways.

1. The old oil palms over 25 years of age have lower yields and growers have to pull them down and replant them. The palm trunks could be used by chopping them into small pieces and leaving them to be digested or used as tillage to add nutrients to the soil, or producing hard fibreboard and wood substitute. This is in accordance with the idea of Oonjittichai (1998), who studied utilising agricultural and industrial residue such as oil palm trunks, leaves, and empty fruit bunches for the production of natural wood-replacing products.

2. Empty fruit bunches could be used to cultivate straw mushrooms, to make compost, and to produce biomass energy. The fronds covering the foot of oil palms or between rows of oil palms would preserve moisture in the soil and reduce soil erosion. It would also degrade to nutrients that are useful for oil palms. This is in accordance with the work of Jungniyom (2008), who conducted a study that indicated that empty fruit bunches are not only material for straw mushroom cultivation but can also be used as tough fibre to replace coconut fibres. It also consists of high nutrients and can be used as material to make good quality compost.

3. The idea of utilising residue from palm oil mill, such as oil palm kernel meal, waste palm fibre, sludge, animal feed, and empty fruit bunches to produce biomass energy, is in line with the idea of Papong (2014), who found that biomassbased residues such as empty fruit bunches, fibre from palm shells, oil palm kernel meal, and palm oil sludge have the potential to produce organic fertilisers, electricity, and thermal energy or wood-replacing materials. Moreover, they can be mixed as animal feed to reduce the environmental burden of materials production. The use of oil palm residue would also reduce the amount of waste from the production of oil palm and palm oil at a zero-waste level in the oil palm industry. It would be the maximum use of waste or a process without waste. This idea is also in line with the work of Jungniyom (2008), who stated that in palm oil mills, waste from oil palm extraction accounted for $70 \%$ and would pose problems for the environment. Therefore, the use of the waste not only protects the environment but also generates income for palm oil mills. This income could be used in purchasing raw materials (fresh fruit bunches). It would also help to stabilise the fresh fruit bunch prices, increase the income from the sale of this product, reduce the cost of chemical fertilisers, reduce the use of chemical fertilisers, and reduce environmental impacts. This idea is similar to that of Papong (2014), who suggested that the production of oil palm would impact the environment as the production process uses chemical fertilisers. The environmental impact derived from the process of oil palm cultivation

TABLE 2. REPRESENTS THE SOCIAL RETURN ON INVESTMENT

\begin{tabular}{lc}
\hline \multicolumn{1}{c}{ Utilisation guideline } & Social return on investment \\
\hline 1. Cultivation of straw mushrooms from empty fruit bunches & 2.34 \\
2. Use of oil palm fronds as animal feed & 5.47 \\
3. Use of empty fruit bunches to cover the soil & 0.84 \\
4. Production of compost from residue of palm oil mills & 0.70 \\
5. Accumulation of oil palm fronds & 1.44 \\
6. Production of compost from empty fruit bunches & 0.80 \\
7. Production of hard fibreboard from old oil palm & 0.35 \\
\hline
\end{tabular}


would affect the entire production chain. Therefore, by decreasing the use of chemical fertilisers, the environmental impact of oil palm and oil palm products would be decreased accordingly.

\section{CONCLUSION}

This study disclosed the utilisation methods of oil palm residue such as tillage, chopping up and digestion to produce biomass energy, mushroom cultivation, animal feed and compost. For each option, the SROI of the utilisation of oil palm residue was found to be between 0.35 and 2.86 . The majority of the utilisation options yielded a SROI lower than 1. Finally, the utilisation of oil palm residue to produce animal feed showed the highest SROI of 2.89 , whereas the use of oil palm residue to produce hard fibreboard demonstrated the lowest SROI of 0.35 .

\section{REFERENCES}

Aeumchan, K (2009). Alternative: Comparative Study of Energy Consumption, Economics and Environmental Impact of Biodiesel Production in a Commercial Scale and Community Scale in Thailand. King Mongkut's University of Technology Thonburi, Bangkok. 53 pp.

Choong, C G and Mckay, A (2014). Sustainability in the Malaysian palm oil industry. J. Cleaner Production, 85: 258-264.

Department of Alternative Energy Development and Efficiency (2015). Alternative Energy Development Plan (AEDP 2015-2036). www.dede. go.th/download / files / AEDP2015_Final_version. pdf, accessed on 7 March 2016.
Jungniyom, T (2008). Zero-waste process in oil palm extraction industries. Hatyai J., 6(2): 164-159.

Malakul, P, Papong, S; Chom-In, T and NoksaNga, S (2011). Life-cycle energy and environmental analysis of biofuels production in Thailand. Kasetsart Engineering J., 24(75): 26-40.

Office of Agricultural Economics (2014). Palm oil industry strategy 2004-2029. http://www. oae.go.th / download / research / 2557/Oil_palm industry.pdf, accessed on 7 March 2016.

Office of Agricultural Economics (2015). Agricultural statistics of Thailand 2015. www.oae.go.th/ download/forecast/ journalofsep2557forecast.pdf, accessed on 7 March 2016.

Oonjittichai, W (1998). Development of Particle Board Using Agricultural Residue. Royal Department of Forestry, Bangkok, Thailand. 25 pp.

Papong, S (2014). A Study for Guidelines on Sustainable Management of the Palm Oil and its Related Products. Agricultural Research Development Agency (public organization). 6 pp.

Phoochinda, W (2015a). Manual for Integration to Strengthen the Palm Oil Industry: Under the Context of Thailand and ASEAN Economic Community. National Institute of Development Administration, Bangkok, Thailand. $15 \mathrm{pp}$.

Phoochinda, W (2015b). Guidelines to Promote Agricultural Oil Palm to Reduce Greenhouse Gases According to the Standard of Thailand. Agricultural Research Development Agency (public organisation). $6 \mathrm{pp}$.

Social Value UK (2019). Calculate the SROI. http: / / www.socialvalueuk.org/app/uploads / 2016/03/ SROI_Guide-Stage5.pdf, accessed on 20 February 2016. 